Article

\title{
Proposed Green Development Reporting Framework for Enterprises from a Life-Cycle Perspective and a Case Study in China
}

\author{
Ning Ding ${ }^{1, *}$, Xinhui Ruan ${ }^{1,2}$ and Jianxin Yang ${ }^{1,2}$ \\ 1 State Key Laboratory of Urban and Regional Ecology, Research Center for Eco-Environmental Sciences, \\ Chinese Academy of Sciences, Beijing 100085, China; xhruan_st@rcees.ac.cn (X.R.); yangjx@rcees.ac.cn (J.Y.) \\ 2 Research Center for Eco-Environmental Sciences, University of Chinese Academy of Sciences, \\ Beijing 100049, China \\ * Correspondence: dingning06@163.com
}

Received: 27 October 2019; Accepted: 24 November 2019; Published: 2 December 2019

\begin{abstract}
Green development is becoming prioritized in industrial settings and manufacturing. Under the current trend of green development, the status of the green development of enterprises is not clear. Evaluation indicators of green development are required, especially given that China has issued many green development policies, as well as special funding support. Reporting is an important tool to foster communication among governments, the public, enterprises, and stakeholders, as well as to assess advances in, and provide guidance, toward realizing green development. The purpose of the present study was to establish a green development report framework and green development indicators for enterprises, with an application to a case study of a textile company in China. The green development reporting framework was based on a life-cycle assessment method, which is an index system constructed to combine quantitative and qualitative indicators, process control and outcome-oriented indicators within the scope of both life-cycle and factory boundaries. This index system included definitions and calculations methods of environmental and resource indicators that can comprehensively reflect green development. By using empirical data from 2017 in the case study, the framework and indicators were further described, and the effects of relevant terms were noted. The green development reporting framework and case study herein can help enterprises understand the concept of green development, self-inspection, self-comparison, communicate advancements, and ultimately improve their level of green development.
\end{abstract}

Keywords: enterprise; green development; life-cycle assessment; green design; green products

\section{Introduction}

Green development (GD) can be defined as an innovative economic development model that recognizes the constraints of environmental and ecological carrying capacity and strives to achieve sustainable development (SD) with environmental protection as a major focus [1]; in other words, GD represents a pathway for economic growth that promotes sustainable natural resource use and provides an alternative outlook to typical industrial economic growth. In China, since the central government proposed the concept of GD in the 12th Five Year Plan in 2011, the theoretical framework and practice of GD have become an indispensable research interest surrounding policy discussions [2].

GD has been applied at various system scales. In particular, enterprises are the major energy consumers and environmental polluters [3]. Thus, enterprises must protect the environment, realize sustainable resource use, and establish eco-industries with the aim of achieving and enhancing GD $[4,5]$. Enterprises may practice GD for the following reasons. First, it can strengthen the competitiveness of an enterprise and can thus confer economic benefits $[3,6,7]$. Second, policy 
requirements are becoming a major driver of GD. In China in particular, the government has released various policies to improve enterprise GD, including special funding support. China has released GD strategies and policies for different sectors [8], such as the "Green development plan of industry 2016-2020," and has conducted specific projects to enhance GD, such as demonstrations of enterprise ecological design, green products, green plants, green parks, etc. Such policies and actions are encouraging and supporting enterprises to adopt GD practices.

Given the adoption of governmental policies, it is worrying to note that the status of the GD of enterprises is not clear. How to evaluate and reveal the GD of enterprises has become a problem that needs to be solved. The GD evaluations of regions and industrial parks have been studied. These evaluation systems focused on the indexes of GDP, total environment emissions, ecological efficiency, etc. [9-11]. The regional index is not suitable for enterprises, which is too simplistic at the enterprises level. The literature refers to the GD of enterprises by mainly focusing on three aspects: the effect factors of GD behavior and performance in enterprises, sustainability reporting (SR) and the evaluation of sustainability, and the performance evaluation of specific GD measures.

$\mathrm{Li}$ et al. found that the GD of industrial enterprises has become the focus of attention of all parties [12]. There are some researchers that have explored the driving factors of GD behavior and performance in enterprises. They found some key factors, such as environmental education, external environmental pressures and opportunities, policy opportunities, market environment and public supervision, etc. [12-15]. The GD performance of industrial enterprises includes corporate financial performance, corporate environmental performance, and corporate social performance [12]. However, these studies did not provide specific indicators for GD performance.

SR is used to disseminate information on and for enterprises. SR encompasses multidimensional (e.g., environment, human rights, actual and best labor practices, product responsibility, and society) longitudinal quantitative and qualitative data that is available to the public $[16,17]$; most corporations use the Global Reporting Initiative (GRI) SR standard [18,19]. Researchers investigated the indicators of SR by analyzing 94 reports, which can be classified to the three widely accepted dimensions of sustainability, namely environment, economy, and society [20]. Similar to SR, some researchers put forward an evaluation model of enterprises based on a triple bottom line [3,21]. However, although these studies contain some content related to the environment, it cannot adequately show or encourage GD, especially given the brevity of the quantitative index used in SR [22].

The performance evaluation of specific GD measures includes the green supply chain [23-25], green manufacturing [26], circular economy, etc. [27-29]. For specific GD measures, the index system is more targeted. For example, the circular economy index pays more attention to resources and the green supply chain index pays more attention to emissions reduction and supplier management. Although these studies can evaluate the performance of specific GD measures, they could not fully reveal the GD of enterprises. The GD evaluation of enterprises should be comprehensive, including management, GD measures, and specific indicators, as well as being related to local policy. In conclusion, the existing studies have not presented an adequate evaluation framework for the GD of enterprises. Therefore, there is an urgent need to develop a GD evaluation index of enterprises. Additionally, collaboration and communication among government agencies, industrial segments, and companies to accelerate the integration of GD into policies and practices is also significant. Reporting, as a communication tool, could be a highly influential driver for organizational changes toward GD [30]. In this context, the purpose of this study is to create a GD reporting (GDR) framework, including a series of indicators.

In addition, there is an urgent need for novel approaches to GD [31]. Life-cycle assessment (LCA) is a widely used tool for environmental assessment and management that considers the whole life cycle of products [32-34]. It can also be used to support GD [35,36]. LCA is an important decision-support tool that, among other functions, allows companies to benchmark and optimize the environmental performance of products or for authorities to design policies for green consumption and production.

Given this background, this paper develops a framework for GDR and establishes a GD index based on the life-cycle perspective for the first time. Then, a case study of the application of this framework as 
applied to a textile company is presented. Through effective enterprise GDR, stakeholders, the public, and governmental agencies can better understand the status of GD of enterprises, forcing enterprises to enhance green design, create GD management systems, and improve green manufacturing practices, with the overall aim of achieving GD.

\section{Method and Data}

\subsection{GDR Framework}

The GDR framework relies on a series of indicators to represent the state of the GD of enterprises and is divided into four main components: enterprise profile, quantitative index, qualitative index, and GD management (Figure 1). Here, the GD index considers both the qualitative and quantitative indices. Twenty quantitative indexes and eight qualitative indexes were created. The qualitative indexes describe the GD measures and achievements of enterprises, whereas the quantitative indexes use specific data to calculate the -values of GD. This information can be used to compare enterprises or to represent temporal changes within an enterprise in order to show the degree of GD and the potential of the enterprise.

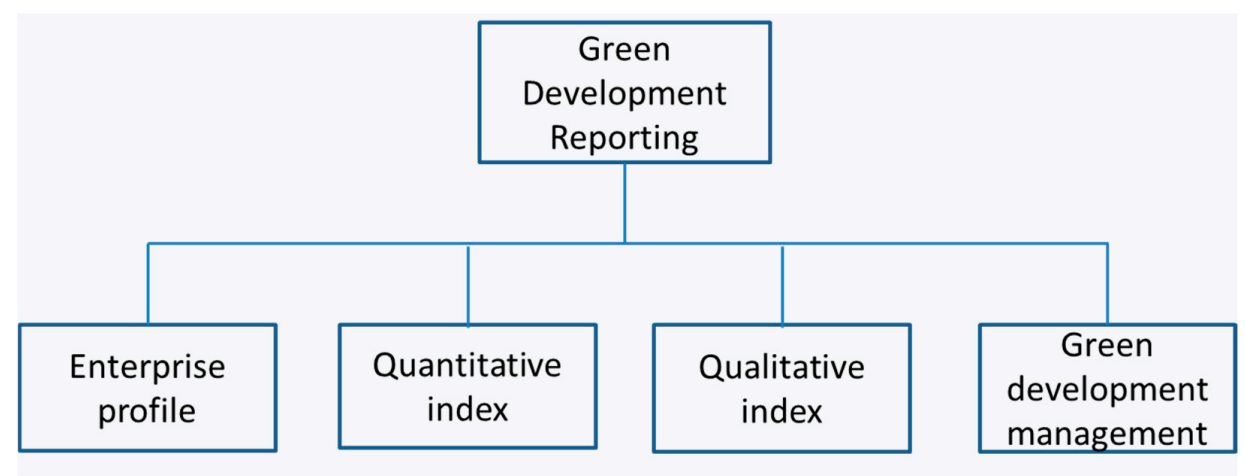

Figure 1. Framework of the proposed green development reporting (GDR).

Within this overall scope, the LCA approach was chosen as the foundational method on which the GDR was developed. First, the establishment of the GDR and index was based on the perspective of the life cycle. The scope included the product design stage, raw material procurement, manufacturing, logistics, usage, and finally recycling and/or disposal. Second, LCA was used to quantify the GD indicators, which is an important component of the index.

\subsection{Outline of the GDR Method}

(1) Temporal application: GDR should be performed at a regular interval (annual is better) to support the assessment of the progression of GD work and indicators.

(2) Scope definition: to define the scope of GDR, the system boundary must be clearly described and defined, including LCA and factory boundaries. The scope of GDR should cover the whole life cycle of the products used and developed by the enterprise, including raw material procurement, research and development, manufacturing, sales, and recycling.

(3) Data description and metadata collection: All data used for the quantitative indicators should be clearly described, including the scope of data collection, the methods of collection, processing, accounting, and accounting tools.

(4) Compilation and evaluation: The standards or norms used in GDR should be presented, while also taking into consideration the specific conditions and actual work performed by all the departments within the enterprise.

(5) Disclosure requirements: The GDR should be made readily publicly available, for example, by posting on the company's website. 


\subsection{Description of the Four Main Components}

\subsubsection{Company Profile}

This component should be completed to provide a general snapshot of the enterprise. It provides readers (e.g., researchers, policy makers, etc.) with basic information, such as the origin, history, development course, products, production capacity, and market of the enterprise. The main contents are listed in Table 1.

Table 1. Company profile information.

\begin{tabular}{|c|c|}
\hline Category & Content \\
\hline \multirow{5}{*}{ Basic information } & Development history \\
\hline & Organization structure \\
\hline & Corporate culture \\
\hline & Staff profile \\
\hline & $\ldots \cdots$ \\
\hline \multirow{4}{*}{ Product(s) } & Main product(s) \\
\hline & Production capacity \\
\hline & Production value \\
\hline & Market occupancy \\
\hline \multirow{5}{*}{ Production } & Production process \\
\hline & Equipment used \\
\hline & Production distribution \\
\hline & Research and development \\
\hline & $\cdots \cdots$ \\
\hline \multirow{3}{*}{ Achievements } & Honorary awards \\
\hline & Patents \\
\hline & $\ldots \ldots$ \\
\hline Other & Other circumstances requiring explanation \\
\hline
\end{tabular}

\subsubsection{Qualitative Index}

The qualitative index includes sections to describe the GD status and the ability of the enterprise to work toward meeting GD characteristics and measures. The qualitative index is broadly divided into the life-cycle process control index and the outcome-oriented index (Figure 2). The process control index considers the whole life cycle of products from the perspectives of green design, green manufacturing, green logistics, green packaging, and green recycling. Enterprises are required to proceed from these processes and describe their relevant capabilities and measures.

Policies in China have been enacted to encourage the adoption of green products, green factories, and a green supply chain, which is assessed in the outcome-oriented index, representing the GD level of enterprises. For instance, enterprises should describe whether they have acquired certifications for green products, green factories, and green supply chains, and if not, what they have done to work toward improving these three aspects. 


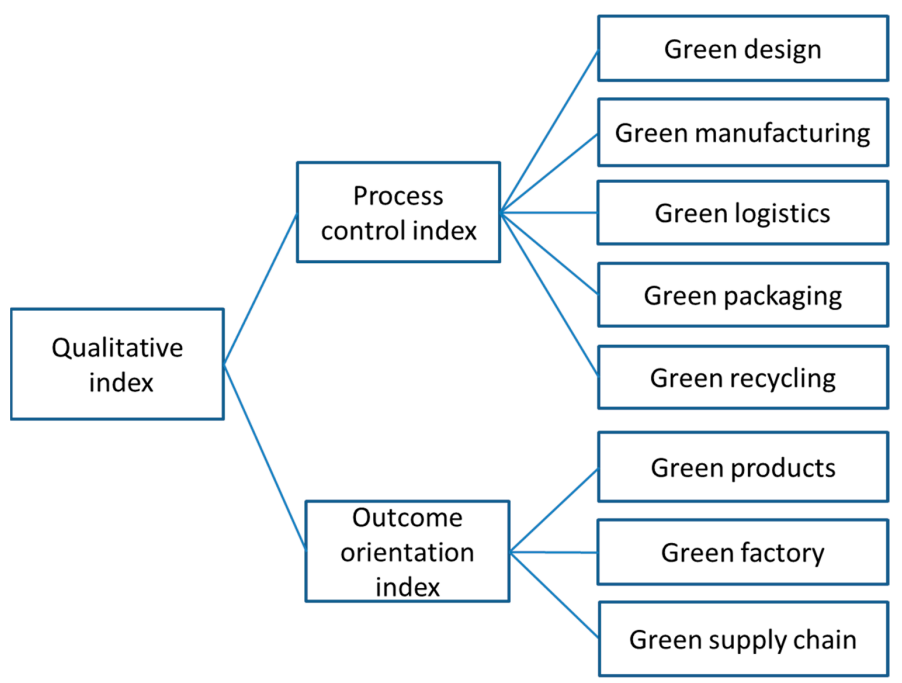

Figure 2. Qualitative index within the GDR.

Life-Cycle Process Control Indicators

\section{(1) Green Design}

Green design is a valuable approach for the reduction of the environmental impact associated with a product system by introducing environmental considerations early in the design process [37,38]. This indicator shows the capacity for, and measures taken toward, achieving green design. Green design capacity includes green design tool construction and green design personnel allocation. Green design tools include LCA, computer-aided integrated design tools, diagram tools, design for X approaches, etc. LCA is recommended as the main approach, whereas other methods can be applied to provide auxiliary information [39]. In terms of green design measures, resource consumption and environmental impacts are considered in the processes of green material selection design, green manufacturing process design, product recyclable design, product dismountable function design, green packaging design, green logistics design, and green recycling, as well as utilization design.

\section{(2) Green Manufacturing}

Green manufacturing describes the implemented technologies and workplace practices that can improve the environmental impact of the production processes. Green manufacturing can lead to lower raw material costs, higher production efficiency, reduced environmental impacts and occupational safety expenses, and an improved corporate image [40,41]. Thus, this indicator can indicate the capacity for, and measures applied toward, achieving green manufacturing. Green manufacturing also describes the various production links in the production life cycle, highlighting the green manufacturing measures implemented by enterprises, and the implementation of green technology [42], such as energy-saving and emissions reduction technology transformation, the use of environmental protection measures, and the application of energy-saving and environmental protection equipment. Techniques to achieve green manufacturing include lean manufacturing, zero emissions measures, and the implementation of environmental standards (e.g., International Standardization Organization (ISO) 14000, ISO 14001, etc.) [43].

\section{(3) Green Logistics}

With the growth of the global economy and the worldwide network of supply chains, logistics have become increasingly complex and large in scale. Therefore, green logistics is an important aspect of modern production systems, which relates to planning, controlling, and implementing the flow of logistics by incorporating modern logistics techniques with the aim of minimizing environmental impacts [44]. Green logistics focuses on material handling, waste management, 
packaging, and transport [45], and can encourage enterprises to enhance GD at the logistics stage. Green logistics management and control should be performed at different life cycle stages, such as raw material procurement, energy supply, transportation within the manufacturing system, sales logistics, and recycling logistics. Many measures have been considered, such as delivery optimization (e.g., improved delivery routes/scheduling and addition of backhaul movements to reduce the number of trips) [46].

It is advised that a green logistics platform should be built to realize the informatization of logistics over the whole life cycle of products, which can then be used to inform logistics management. Thus, this could help to conduct analyses of the logistics capability, logistics assets, transportation safety, transportation cost, transportation performance, transportation quality loss, etc., and comprehensively improve logistics efficiency.

\section{(4) Green Packaging}

Green packaging can be considered packaging design that explicitly or implicitly helps achieve eco-friendliness [47]. A previous study has defined green packaging as packaging with a comparatively low environmental impact based on a LCA [48]. Within the GDR framework, this indicator is set to require enterprises to reduce the total materials used for packaging and select greener materials for packing, as well as describe the measures and effect of green packaging.

If the enterprise produces its own packaging, measures toward green packaging should include promoting the use of recyclable or compostable packaging, using reusable coaming boxes, the replacement of single use cartons by plastic trays and storage cages, and the launch of direct distribution in order to reduce the investment in disposable packaging and reduce packaging costs. If packaging is supplied by other enterprises, the enterprise should develop and implement guidelines for packaging selection and the periodic evaluation of suppliers that includes environmental requirements.

\section{(5) Green Recycling}

The green recycling index encompasses the monitoring of products after they leave the factory to improve the use and disposal practices of products and encourage the creation of, or participation in, recycling programs. Within the GDR framework, three kinds of recycling platforms are defined: irregular recycling, producer consortium, and professional third party [49].

Specific measures include the establishment of a green recycling system, including the collection of renewable resources through an efficient recycling network that comprises the classification, sorting, reuse, or disposal of items according to the concepts of environmental protection and health and safety. Renewable resource recycling enterprises are encouraged to establish transparent and traceable systems and record relevant information with modern information technologies, such as bar codes and the internet, to ensure closed-loop traceability.

Outcome-Oriented Index

\section{(1) Green Products}

The green product index represents the production capacity and status of green products, whereby the enterprise must declare whether the product has passed relevant green product standard evaluations and obtained relevant certifications (national or international). In addition, enterprises must describe the research and development of green products and related plans.

\section{(2) Green Factory}

Green factory refers to the premise of ensuring the product function, quality, and health and safety of employees in the manufacturing process, while meeting the corresponding requirements in terms of the infrastructure, management system, energy and resource input, product, and environmental emission. For instance, this index includes whether the enterprise has passed national and/or provincial 
green factory evaluations and whether it has won any honorary titles as a national/provincial green factory. Finally, measures taken toward achieving green factory requirements should be described.

\section{(3) Green Supply Chain}

Green supply chains have a substantial impact on the environment, especially in terms of emissions and pollution. Thus, enterprises should minimize environmental impacts by integrating environmental concerns into supply chain operations [50], as the adoption of sustainable practices has a critical role in improving the environmental performance of enterprises with global networks [51]. Therefore, this indicator reflects the upstream processes of enterprises to help build a green supply system.

Within this index, the enterprise must declare the steps taken toward realizing a green supply chain system, including controls on upstream suppliers, the procedures and tools used during the supply of raw materials, and the realized beneficial effects.

\subsubsection{Quantitative Index}

The quantitative index includes indicators of green products, green design, green manufacturing, environmental performance, and resource efficiency. We set and defined 20 quantitative indicators to evaluate GD in this study (Table 2). The creation of green products is one of the ultimate goals of GD, given that products are the pillar of enterprise development. Therefore, a quantitative measure of green products is needed. Furthermore, green design and green manufacturing are important aspects of GD and form the basis of green products. Therefore, quantitative indicators of these aspects are used to force enterprises to improve their capability for green design and their degree of green manufacturing. Finally, resource and environmental indicators are set to control the enterprise's resource consumption and environmental emissions.

Table 2. Quantitative indices within the GDR framework.

\begin{tabular}{|c|c|}
\hline First-Level Indicators & Second-Level Indicators \\
\hline \multirow{4}{*}{ Green product } & Ratio of green product production value \\
\hline & Energy consumption per unit product \\
\hline & Water consumption per unit product \\
\hline & Environment impacts based on LCA \\
\hline \multirow{4}{*}{ Green design } & Ratio of green materials \\
\hline & Ratio of green investments \\
\hline & Recoverability rate of products \\
\hline & Removable rate of products \\
\hline \multirow{2}{*}{ Green manufacturing } & Ratio of green equipment \\
\hline & Green transformation rate of process \\
\hline \multirow{4}{*}{ Environment performance } & Carbon emission reduction per unit product \\
\hline & Energy savings per unit product \\
\hline & Electricity savings per unit product \\
\hline & Reduction in major pollutants per unit product (including $\mathrm{COD}, \mathrm{SO}_{2}, \mathrm{NO}_{\mathrm{x}}$ etc.) \\
\hline \multirow{6}{*}{ Resource efficiency } & Output value per unit of energy consumption \\
\hline & Water reuse rate \\
\hline & Ratio of renewable energy usage \\
\hline & Material consumption per unit product \\
\hline & Output value per unit land use \\
\hline & Comprehensive utilization rate of industrial solid waste \\
\hline
\end{tabular}




\section{Green Products}

(1) Ratio of green product production value

$$
G P_{r}=\frac{G P_{V}}{P_{V}}
$$

where $G P_{r}$ is the ratio of green product to the total production value, $G P_{V}$ is the value of green products, and $P_{V}$ is the value of all production in one year.

(2) Energy consumption per unit product

$$
E=\frac{E_{t}}{P}
$$

where $E$ is the energy consumption per unit product, $E_{t}$ is total energy consumption (MJ), and $P$ is the total production.

(3) Fresh water consumption per unit product

$$
W=\frac{W_{t}}{P}
$$

where $W$ is the fresh water consumption per unit product and $W_{t}$ is water consumption $\left(\mathrm{m}^{3}\right)$.

(4) Environmental impact based on an LCA

This indicator should be calculated using an LCA with consideration of the whole life cycle of the product. For example, ore mining, raw material procurement, material processing and production, manufacturing, assembly, usage, and disposal and treatment should all be included. The life-cycle environmental impact method should be chosen according to the characteristics of the products. For instance, common methods, such as CML 2001, Eco-indicator 99 and ReCiPe can be applied to the LCA, and the LCA of products should be carried out according to the ISO standard.

A given enterprise may produce many types of products. In such cases, LCAs can be carried out gradually; for instance, LCAs can be performed for one or several products with each released GDR.

\section{Green Design}

(1) Ratio of green materials

$$
M_{g r}=\frac{M_{g}}{M_{t}}
$$

where $M_{g r}$ is the ratio of green materials to total materials, $M_{g}$ is the green material consumption, and $M_{t}$ is the total material consumption.

(2) Ratio of green investments

$$
I_{g r}=\frac{I_{g}}{I_{t}}
$$

where $I_{g r}$ is the ratio of investments into green technology for energy savings and emissions reduction to total investments, $I_{g}$ is the investment into green technology, and $I_{t}$ is the investment into total technology transformation.

(3) Recoverability rate of products

The recoverability rate of products refers to the proportion of the quality of the product that can be recycled to the quality of the product, including the reused part, the recycling part, and the energy recovery part.

$$
R_{r}=\frac{Q_{r}}{Q}
$$


where $R_{r}$ is the recoverability rate of products; $Q_{r}$ is the quality of the product recycled (including reuse, recycling, and energy recovery); and $Q$ is the total quality of the products.

(4) Dismountable rate of products

The dismountable rate of products refers to the proportion of the quality of the product that can be dismounted to the quality of the product. The improvement of dismountable rate helps to reuse the products.

$$
R_{d}=\frac{Q_{d}}{Q}
$$

where $R_{d}$ is the dismountable rate of products and $Q_{d}$ is the quality of the dismounted parts of product.

Green Manufacturing

(1) Ratio of green equipment

$$
E_{g r}=\frac{E_{g}}{E_{t}}
$$

where $E_{g r}$ is the ratio of green equipment, $E_{g}$ is the number of pieces of green equipment that offers energy consumption and emissions reductions; $E_{t}$ is the total number of pieces of equipment used by the enterprise.

(2) Green transformation rate of process

$$
R_{g r}=\frac{R_{g}}{R_{t}}
$$

where $R_{g r}$ is the green transformation rate of the process, $R_{g}$ is the amount of the process that has been transformed to be more green, and $R_{t}$ is the total amount of processes.

\section{Environmental Performance}

Environmental performance is used to describe the environmental benefits achieved by enterprises through GD measures. Because this represents a change over time, these indices are calculated as a biennial ratio.

(1) Carbon emission reduction per unit of product

$$
C_{v d}=\frac{C_{l}}{P_{l}}-\frac{C_{y}}{P_{y}}
$$

where $C_{v d}$ is the reduction of carbon emissions per unit of product compared with the previous year, $C_{l}$ is the carbon emissions from the previous year, $P_{l}$ is the production of the previous year, $C_{y}$ is the carbon emissions of the current year, and $P_{y}$ is the production of the current year.

(2) Energy savings per unit of product

$$
E_{v d}=\frac{E_{l}}{P_{l}}-\frac{E_{y}}{P_{y}}
$$

where $E_{v d}$ is the reduction in energy consumption per unit of product compared with the previous year, $E_{l}$ is the energy consumption of the previous year, and $E_{y}$ is the energy consumption of the current year.

(3) Electricity savings per unit of product

$$
P_{v d}=\frac{E_{l}}{P_{l}}-\frac{E_{y}}{P_{y}}
$$


where $P_{v d}$ is the reduction in electricity consumption per unit of product compared with the previous year, $E_{l}$ is the electricity consumption of the previous year, and $E_{y}$ is the electricity consumption of the current year.

(4) Reduction in major pollutants per unit of product

$$
M_{v d}=\frac{M_{l}}{P_{l}}-\frac{M_{y}}{P_{y}}
$$

where $M_{v d}$ is the reduction in major pollutants per unit of output value (e.g., chemical oxygen demand (COD), $\mathrm{SO}_{2}, \mathrm{NO}_{\mathrm{x}}$, etc.); $M_{l}$ is the pollutant emissions from the previous year; and $M_{y}$ is the pollutant emissions of the current year.

\section{Resource Efficiency}

This index represents the utilization efficiency of various resources, such as energy, water, raw materials, land use, and other resources.

(1) Output value per unit of energy consumption

$$
E_{v}=\frac{P_{V}}{E_{t}}
$$

where $E_{v}$ is the energy consumption per unit of output value, $E_{t}$ is the energy consumption (MJ), and $P_{V}$ is the total output value.

(2) Water reuse rate

$$
R_{w}=\frac{W_{r}}{W_{C}}
$$

where $R_{w}$ is the reuse rate of water resources, $W_{r}$ is the amount of water resources that have been reused, and $W_{C}$ is the total water resource consumption.

(3) Ratio of renewable energy usage

$$
R_{e}=\frac{E_{r}}{E_{C}}
$$

where $R_{e}$ is the ratio of renewable energy usage, $E_{r}$ is the renewable energy consumption, and $E_{C}$ is the total energy consumption.

(4) Material consumption per unit product

$$
M_{e}=\frac{M_{\mathcal{C}}}{P}
$$

where $M_{e}$ is the material consumption per unit product, $M_{c}$ is the total material consumption, and $P$ is the production.

(5) Output value per unit land use

$$
L_{V}=\frac{P_{V}}{L}
$$

where $L_{V}$ is the area of land used per unit output value and $L$ is the area of land used by the enterprise.

For this calculation, the plot ratio (i.e., the floor area of the factory to the total land area) must meet the specifications of the "Industrial Project Construction Land Control Index." Efficient use of land area is achieved when the industrial land area output intensity is equal to or exceeds the relevant national or local requirements. 
(6) Comprehensive utilization rate of industrial solid waste

$$
R_{s w}=\frac{S W_{r}}{S W+S W_{z}} \times 100 \%,
$$

where $R_{s w}$ is the comprehensive utilization rate of industrial solid waste, $S W_{r}$ is the comprehensive utilization amount of industrial solid waste (excluding outsourcing), $S W$ is the amount of industrial solid waste generated, and $S W_{z}$ is the amount of solid waste stored from the previous year.

\subsubsection{GD Management}

GD management includes system planning, green technology innovation, and GD action.

GD Management Planning System

The purpose of the GD management index is to support the establishment of a green management system, using GD as the guiding ideology; this index comprises two parts: GD planning and specific measures toward achieving GD. GD planning includes medium-term and long-term plans for the GD of enterprises, as well as quantitative annual targets and implementation plans. A GD management group should be established to be responsible for the system's construction, implementation, and assessment; to reward successful GD; and to establish a target responsibility system. Specific measures represent the establishment of the GD system, including the modules of green design, green manufacturing, green sales, green enterprise culture, etc.

Green Technology Innovation

The green technology innovation index aims to promote enterprises to seize advantageous market positions by researching and developing new products or replacing original products with green products through technological innovation. Meanwhile, economic benefits can be gained by investing in energy conservation and emissions reduction projects. Green technology innovation refers to the innovation achievements of enterprises in green products, energy conservation, and emissions reductions, such as patents and participation in the development of relevant standards.

\section{GD Action}

Enterprises are required to reveal the activities related to increases in employment opportunities, health and safety, impacts on local communities, and GD training and broadcasting. GD training and broadcasting refers to the integration of GD policy into daily work through management, publicizing GD culture to employees, and improving the employee awareness of GD. Staff should be provided regular education and training on GD knowledge, with assessments of the outcomes of such education and training efforts.

\section{Case Study in China}

In order to show how to use this GDR framework, and test the feasibility of the proposed GDR framework and the availability of data to support the indicators, a Chinese textile company was chosen for a case study (hereafter referred to as $\mathrm{H}$ company). It had an integrated production of knitting, dyeing, printing, and finishing, with an annual output of about 87 million $\mathrm{kg}$ and more than 6500 employees.

For the purpose of this case study, focus was placed on the quantitative and qualitative indicators. The company profile is omitted for privacy. When completing the GDR, additional descriptions of the index should be presented below each indicator when necessary in the GDR, including but not limited to the descriptions under each indicator in this paper.

We investigated the H company for this study. First, we introduced the background of GDR and the composition of research indicators to relevant personnel of the enterprise, explained the data we 
needed, and asked them to fill in the survey form (Table S1). At the same time, we held a discussion with five people from the enterprise production department, the standardization office, and other relevant departments to get a general understanding of the basic work done regarding several aspects of GDR in recent years and the year 2017, and asked for detailed information on the key work that we thought could support the indicators. H company also provided related profile information, such as a storage ledger of raw and auxiliary materials, equipment list, investment statistic, list of technical transformation and equipment update, clean production report, green factory declaration report, and other materials.

\subsection{Quantitative Index}

The quantitative indicators for $\mathrm{H}$ company are listed in Table S2. All calculations were performed for 2017.

\subsubsection{Green Products}

(1) Ratio of green product production value

The products that passed national or global green product (or related) certification should be covered. This index aims to increase the proportion of green products in enterprises, urge enterprises to create green products, and actively participate in the certification and evaluation of green products. The chemical fiber knitting products produced by $\mathrm{H}$ company have passed the ecological design Standard 100 through OEKO-TEX certification. The company's output value of this product was -60938.1 million Yuan, and the total output value of the company was 468,754.73 million Yuan; therefore, $G P_{r}=13 \%$.

(2) Energy consumption per unit product

The energy consumed, such as from coal, gasoline, natural gas, and electricity, should be summarized. In 2017, the company produced a total of 72,131.2 $t$ of printing and dyeing cloth and printed cloth, and consumed a total of $89,652 \mathrm{t}$ of standard coal; therefore, $E=1.355 \mathrm{t}$ standard coal/t product.

(3) Fresh water consumption per unit product

In 2017, the company used a total of 8.4 million $t$ of fresh water; therefore, $W=116.3 \mathrm{t}$ water/t product.

(4) Environmental impacts based on a LCA

The data for the LCA was collected from the process and suppliers. In 2017, the enterprise performed an LCA of its main products; the results provided by H company are summarized in Table 3 . One of their products, named light cotton lycra, was studied based on CML 2001 [52] using Gabi [53]. When completing a GDR, additional descriptions should be provided where necessary, such as the results analysis or presentation of conclusions from the LCA. 
Table 3. Results of the LCA of the main products produced by H company.

\begin{tabular}{ccc}
\hline Environment Impacts Based on CML2001 & Units & Value \\
\hline Abiotic depletion (ADP elements) & $\mathrm{kg} \mathrm{Sb}$ eq. & $5.66 \times 10^{-5}$ \\
Abiotic depletion (ADP fossil) & $\mathrm{MJ}$ & 222 \\
Acidification potential (AP) & $\mathrm{kg} \mathrm{SO}$ eq. & 0.06 \\
Eutrophication potential (EP) & $\mathrm{kg} \mathrm{Phosphate} \mathrm{eq.}$ & 0.0323 \\
Freshwater aquatic ecotoxicity pot. (FAETP inf.) & $\mathrm{kg}$ Phosphate eq. & 0.73 \\
Global warming potential (GWP 100 years) & $\mathrm{kg} \mathrm{CO}$ eq. & 17.7 \\
Global warming potential (GWP 100 years), excl biogenic carbon & $\mathrm{kg} \mathrm{CO}$ eq. & 19.4 \\
Human toxicity potential (HTP inf.) & $\mathrm{kg} \mathrm{DCB} \mathrm{eq.}$ & 4.69 \\
Marine aquatic ecotoxicity potential (MAETP inf.) & $\mathrm{kg} \mathrm{DCB} \mathrm{eq.}$ & 2440 \\
Ozone layer depletion potential (ODP, steady state) & $\mathrm{kg} \mathrm{R11} \mathrm{eq.}$ & $1.41 \times 10^{-10}$ \\
Photochemical ozone creation potential (POCP) & $\mathrm{kg} \mathrm{Ethene} \mathrm{eq.}$ & $5.75 \times 10^{-3}$ \\
Terrestric ecotoxicity potential (TETP inf.) & $\mathrm{kg} \mathrm{DCB} \mathrm{eq.}$ & 0.0951 \\
\hline
\end{tabular}

\subsubsection{Green Design}

(1) Ratio of green materials

Green materials are the basis of green products. The materials that passed the national or global green products certification should be covered. According to the company's storage ledger of raw and auxiliary materials and the company's list of materials, the dyes and auxiliaries used met the ecological design Standard 100 through OEKO-TEX and ZDHC MRSL Version 1.1 certification requirements. The amount of green raw material (dye) used was $260.55 \mathrm{t}$, the amount of green raw material (auxiliary agent) used was $768.86 \mathrm{t}$, and the amount of green raw material (chemical material) used was $0 \mathrm{t}$; therefore, $M_{g r}=50 \%$.

(2) Ratio of green investments

The data should be acquired from the annual investment statistics and the list of technical transformation and the equipment update. This indicator aims to encourage companies to invest in technological improvement. In 2017, H company implemented a green transformation project to build an energy-saving control system for thermal power plants, with a total investment of 23.32 million Yuan. The total investment was 118.3902 million Yuan in 2017; therefore, $I_{g r}=19.7 \%$.

(3) Recoverability rate of products

Some companies do not cover the recovery of products, or they are intermediate product suppliers. They can describe the work related to green design for recycling. The recycling of waste textiles has long been a concern, especially given that the comprehensive utilization rate of waste textiles in China is only $15 \%$ [54]. In 2017, the company cooperated with downstream garment users to carry out textile recycling research.

(4) Dismountable rate

This index is more used in machining enterprises. It does not apply to textile enterprises.

\subsubsection{Green Manufacturing}

\section{(1) Ratio of green equipment}

The data of this indicator should be collected from the equipment list. This indicator is set to encourage the company to update environmental protection equipment, which is recommended by government. H company had 802 sets of high-efficiency energy-saving equipment, and the total number of pieces of equipment was 6465 sets; therefore, $E_{g r}=12.4 \%$. 
(2) Green transformation rate of the process

This indicator is set to encourage the company to focus on the production process and raise the level of green manufacturing. The main production processes of the company were as follows: weaving, fixed embryo, dyeing, printing, and finalizing. At present, all the processes except fixed embryo have undergone green transformation; therefore, $R_{g r}=4 / 5=80 \%$.

\subsubsection{Environmental Performance}

(1) Energy savings per unit product

The comprehensive energy consumption of the enterprise in 2017 and 2016 was 153,279 $t$ of standard coal and $151,045 \mathrm{t}$ of standard coal, respectively. Therefore, $E_{v d}=0.157 \mathrm{t}$ standard coal $/ \mathrm{t}$ product, equivalent to an energy savings rate of $7 \%$. This indicates the effect of technology transformation and improvement.

(2) Carbon emissions reduction per unit product

Some enterprises carry out a carbon verification or calculate the carbon emissions according to the energy consumption and process emissions. The enterprise can show the carbon emissions of total products or show one or more types of products. In 2017 and 2016, H company performed carbon verification; the carbon verification was performed by qualified third party. Carbon emissions include indirect emissions from purchased electricity, direct emissions from fuel combustion, and direct emissions from the decomposition of carbonate dyeing fertilizer. The carbon emissions were 504,197 $\mathrm{t}$ and 467,962 t, respectively. The production in 2017 and 2016 was 721 million $t$ and 662 million $t$, respectively. Therefore, $C_{v d}=0.013 \mathrm{t} / \mathrm{t}$ product, equivalent to a carbon emission reduction rate of $14 \%$. This means that the company adopted cleaner energy or reduced their energy consumption.

(3) Electricity savings per unit product

The electricity consumption of the enterprise in 2017 and 2016 was $5856 \mathrm{kWh}$ and $6257 \mathrm{kWh}$, respectively. Therefore, $P_{v d}=0.013 \mathrm{kWh} / \mathrm{t}$ product, equivalent to an electricity savings rate of $14 \%$. Electricity was the main energy and source of cost. Electricity saving may result from technology improvement.

(4) Reduction in major pollutants per unit product

According to the company's "key pollutant discharge unit environmental information disclosure format specification table," its annual COD discharge in 2016 was $309.32 \mathrm{t}$ and in 2017, its COD discharge was 250.66t; therefore, $M_{v d}$ for $\mathrm{COD}=0.0012 \mathrm{t} / \mathrm{t}$ product, equivalent to an emissions reduction rate of $25 \%$.

Although only COD was considered in this example, all pollutants relevant to the given enterprise (e.g., $\mathrm{SO}_{2}$ and $\mathrm{NO}_{x}$ ) should be calculated. This indicator encourages the company to pay more attention to increasing environment protection equipment and reducing environmental emissions.

\subsubsection{Resource Efficiency}

(1) Output value per energy consumption

Energy consumption per unit of product was calculated. This indicator is related to economy. Its goal is to bring more economic benefits from energy. In 2017, the energy consumption was 153,278.8 $\mathrm{t}$ standard coal, and the output value was 4687.55 billion Yuan; therefore, $E_{v}=0.306$ million Yuan/t standard coal. 
(2) Water reuse rate

Water conservation has always been the goal of enterprises and improving water recycling efficiency is a potential method to achieve this. The freshwater consumption of the enterprise was 8.38 million $\mathrm{t}$, and the consumption of reused water was about 2.93 million $\mathrm{t}$; therefore, $R_{w}=35 \%$.

(3) Ratio of renewable energy usage

Increasing renewable energy efficiency has been the aim of GD [10]. H company began using solar energy in 2017 in a solar energy medium-temperature steam project. The system installation area was $1000 \mathrm{~m}^{2}$ and the rated hours of steam output was $0.5 \mathrm{t}$. The annual energy saving of the project was 7500 tce; therefore, $R_{e}=7500$ tce $/ 153,278.8 \mathrm{t}$ standard coal $=5 \%$, accounting for $5 \%$ of the total energy consumption.

(4) Material consumption per unit product

The goal is to improve the efficiency of raw materials. Reducing the use of raw materials can save on both costs and natural resources. The total consumption of cotton yarn in 2017 was $81,594.3 \mathrm{t}$, the total consumption of dye was 2,605.5 $t$, the total consumption of additives was $7,688.6 t$, and the total consumption of chemical raw materials was $66,913.4 \mathrm{t}$; therefore, $M_{e}=(81,594.3+2605.5+7688.6$ $+66,913.4) / 72,131.2=2.2 \mathrm{t}$ material/t product.

(5) Output value per unit land use

This indicator serves to encourage enterprises to use land more intensively with the aim that the same land will produce more economic value. The company covered an area of $333,450.7 \mathrm{~m}^{2}$; therefore, $L_{V}=4687.55$ million Yuan/333,450.7 $\mathrm{m}^{2}=14,000 \mathrm{Yuan} / \mathrm{m}^{2}$ in 2017.

(6) Comprehensive industrial solid waste utilization rate

This indicator serves to promote the recycling of resources and the legalization of waste disposal and treatment. In H company, sludge was treated by sending it to a combined heat and power supply system after drying and burning it with coal. Slag and ash are sold to qualified companies as raw materials for brick-making. Waste packaging material is recycled by the company, some of which is recycled, and some of which is entrusted to qualified and capable companies for recycling and disposal. The utilization rate could exceed $90 \%$.

\subsection{Qualitative Index}

In order to provide an intuition about how to draw a qualitative index, a brief introduction about $\mathrm{H}$ company is provided. In the official GDR, more details of indicators are needed.

\subsubsection{Indicators of the Life-Cycle Process Control}

(1) Green design

In 2017, $\mathrm{H}$ company built a green design platform, set up a basic database for the textile industry, and evaluated the life cycle of the main products.

(2) Green manufacturing

In 2017, H company carried out several green manufacturing programs. As examples, only three major programs are introduced here: replacement of the air flow dyeing machine, introduction of energy-saving short-process technology, and a motor energy efficiency improvement project. Here, no further details are provided but it is advised that green manufacturing technology should be introduced in a formal GDR. 


\section{(3) Green logistics}

The company had not established a green logistics system; however, the company has tried to reduce energy consumption from transportation. Some measures taken in 2017 include the adoption of electric vehicles and the maximization of loading space usage during transportation.

(4) Green packaging

$\mathrm{H}$ company recycles waste packaging material, some of which is recycled, and some of which is entrusted to qualified and capable companies for recycling and disposal.

(5) Green recycling

In 2017, H company began to establish a product recovery system with the aid of downstream customers.

\subsubsection{Outcome-Oriented Index}

In this section, the GD results of the enterprise are shown. It aims to encourage enterprises to carry out GD work and obtain national or international certification and recognition.

(1) Green products

The company does not have any green product certifications. However, the company's chemical fiber knitting products have passed the ecological design Standard 100 through OEKO-TEX certification. In 2014, the company was listed among the first batch of enterprises in China to demonstrate industrial product ecological design by the Ministry of Industry and Information Technology.

(2) Green factory

H company was recognized as a national green factory in China in 2017; therefore, the company has met the requirements of a green factory. A lot of measures referring to the infrastructure, management system, resource consumption, etc., have been adopted by the company in order to achieve the green factory requirements, such as building a green product design platform, setting up solar energy equipment, carrying out carbon verification, and doing renovation to conserve energy and reduce emissions.

\section{(3) Green supply chain}

The company had not obtained green supply chain certification. However, the company has focused on improving its supply chain, placing strict requirements on suppliers, and asking them to meet environmental protection requirements. Furthermore, the company does not use supplied materials containing toxic and harmful substances that are prohibited by China or the European Union. The company has its own laboratory for the quality control inspection of incoming materials and is also equipped with a corresponding quality inspection center laboratory, which carries out inspections of the finished products to further ensure the quality of the product.

\section{Discussion}

\subsection{Importance of Annual GDRs}

Within the proposed GDR framework, GDRs should be produced on an annual basis to effectively monitor and encourage enterprises to take measures toward GD. Annual reporting has the following advantages: (1) it provides relatively frequent data on the GD measures taken by enterprises, (2) it enables frequent evaluations of the effects of enterprises' GD, (3) it shows relatively high-temporal-resolution trends of the development of technology within a given industry, and (4) it urges enterprises to make innovations every year. Unfortunately, relevant studies to support the "annual report" recommendation were not found. The original intention of the "annual report" is that 
the enterprise should supervise and inspect the green development situation, calculate the indicators every year, analyze the trend of the indicators, and check their progress in green development. We think the "annual report" is an effective way to produce a green development report.

\subsection{Benefits of Using Both Quantitative and Qualitative Indices}

The proposed GDR framework uses a combination of quantitative and qualitative indices. It has the benefits of reflecting GD plans, measures, and effects of enterprises from different perspectives; furthermore, the qualitative index can provide greater flexibility for its application to enterprises in different industries.

For instance, qualitative indicators are used to describe the GD measures of enterprises, whereas quantitative indicators are used to represent the effects of the GD of enterprises. Since enterprises may fall within a wide variety of industries at different nodes of the production life cycle, only the use of quantitative indicators could prevent the consideration of industry-specific characteristics. Thus, enterprises can describe unique GD-related characteristics within their field (e.g., specialized equipment and production technology) within the qualitative index.

\subsection{Combination of Life-Cycle and Factory Boundary Indicators}

The combination of life-cycle and factory boundary indexes can reflect an enterprise's overall GD plan, measures, and effects. In particular, the LCA approach enables the consideration of many indicators. For example, qualitative indicators cover the whole life cycle of products and green supply chain indicators are defined. The most important component of the quantitative index of green products is the calculation of the environmental impact of products using the LCA method. Meanwhile, many indicators can only be represented within the factory boundary, such as environmental benefits. This study focuses on the reduction of environmental emissions achieved by adopting GD measures within the factory boundary, while the quantitative characterization of upstream and downstream effects is reflected in the LCA of green products and green supply chain management.

\subsection{Applicability and Limitations of the Proposed GDR}

This study created a GDR framework with broad applicability to many sectors or industries. Due to the large variety of enterprises and industries, not all indicators in this study may be applicable to all enterprises. For example, the dismountable rate is mostly used in mechanical equipment manufacturing enterprises. Therefore, no mandatory index has been included in the GDR. Moreover, GDR is not currently compulsory, but can instead be used as a tool to help enterprises work toward achieving GD.

This case study supports the feasibility and applicability of applying the proposed framework as follows: (1) By collecting data in the enterprise, it was found that the index data are suitable for the enterprise and easy to obtain; a simple investigation table can cover all data (Table S1). (2) The calculation process shows that the index calculation is convenient. (3) By combining quantitative indicators with qualitative indicators. Quantitative indicators can display GD measures flexibly and can determine and explain quantitative indicators. If the enterprises cannot provide quantitative data, measures and plans can be described using a qualitative index, such as green design and green manufacturing. (4) Indicators cover the life cycle of products, which not only reflects the GD of the enterprise itself, but also reflects the management of the upstream and downstream processes. For example, though the GDR, it was found that H company had not carried out measures toward obtaining a green supply chain, which should be improved in the future.

This study involved some qualitative social indicators in the green action section, including social responsibility, employment, and health and safety. However, there were no quantifiable social indicators. Social impact is relatively complex, and quantitative social indicators should be calculated by developing professional models with employment personnel, salary, and other data. Therefore, further attention should be paid to social LCA (SLCA) in the following research. SLCA, as an important 
aspect of LCA research, has been well-applied, and gradually applied from the product to the enterprise level, with indicators related to stakeholders and quantitative/semi-quantitative methods [55-57]. This can improve the social responsibility and social image of enterprises.

\subsection{Comparison with the SD Index}

GD and SD complement each other well. The essence of both is to choose a development model that fundamentally changes the traditional model [58]. They share the same goal: reducing resource consumption and environmental damage while maintaining moderate growth. Compared to SD, GD has three specific characteristics: (1) The understanding of the ecological environment is different. SD is a development model that focuses on long-term interests and intergenerational equity, and is based on the protection of the ecological environment. While emphasizing the protection of the ecological environment, GD introduces ecological environmental factors into the development model. (2) GD is more focused on economic development [10]. Originating from the notions of green economy, most theories on GD focus on the circular economy, low-carbon economy, and ecological economy [59]. (3) GD is an important part of SD and has the characteristics to promote the process of SD. The general view of GD is that it is a mean required to achieve SD.

SD indicators of the environmental dimension refer to the conditions surrounding human life. The environmental impact is significantly affected by the reclamation and development of enterprises, e.g., the use of hazardous substances, the discharge of wastewater, the emission of harmful gases, and the development of new factories. Enterprises must monitor and effectively reduce the damage to the environment [3].

As a GD indicator at the enterprise level, this study emphasized the ways in which environmental protection can be realized and considered the associated economic factors: (1) This study integrated the economy into the indicators, focusing on resource (energy, land) efficiency. (2) It focused on environmental indicators from the perspective of the life cycle. (3) The indicators in this study not only cover the environmental impact, but also cover the process control that produces the environmental impact. It requires that enterprises implement green design, green manufacturing, and green supply chains to achieve control of sources and process.

\subsection{Implications}

This study established a GDR framework, which can demonstrate and evaluate the effect of GD policy implementation from the management level. It can also provide and urge enterprises to carry out green design, green manufacturing, green supply chain development, and other measures to improve the level of green development. From the perspective of academic research, this study created a set of indexes for GD at the enterprise level. It enriches the GDtheory of enterprise. In addition, it is an application of life-cycle thinking in guiding the GD of enterprises, i.e., product design, material selection, manufacturing, packaging, transportation, and recycling.

\section{Conclusions}

This paper established a GDR framework and a series index for enterprises and presented a case study using empirical data from a textile enterprise in China. The GDR framework was based on the LCA approach; within this framework, an index system was created that combined quantitative and qualitative indicators, as well as the scope of the life-cycle and factory boundaries. The index system provides a theoretical approach for measuring GD using environmental- and resource-based indicators, which can comprehensively reflect GD. The case study of the textile enterprise in China supported the feasibility of applying the GDR framework.

The framework and index system can be used to address the current limitations in practices toward achieving the GD of enterprises. Finally, it provides definitions, interconnections, and the effects of relevant terms within the scope of GD, and lists various measures that can be taken by 
enterprises to encourage GD. Thus, this report is expected to help enterprises to better understand, communicate, and advance toward GD.

The current indicators are only suitable for enterprises' self-inspection and self-comparison. This paper does not provide comprehensive accounting methods to weight indicators or form a unified method and a single index to provide comparisons between different enterprises. This study only provides the framework and ideas for the GDR, aiming to establish and improve the GD work for enterprises. Regarding how to set up evaluation methods, comparison, reward, and punishment should be further studied.

Supplementary Materials: The following are available online at http://www.mdpi.com/2071-1050/11/23/6856/s1, Table S1: Investigation table, Table S2: Quantitative indicators of H company in 2017.

Author Contributions: Conceptualization, N.D. and J.Y.; Methodology, N.D.; Software, X.R.; Investigation, N.D. and X.R.; Writing-Original Draft Preparation, N.D.; Writing-Review \& Editing, N.D.; Funding cquisition, N.D.

Funding: This research was funded by National Natural Science Foundation of China, grant number: 41801217 and Junior Fellowships for Advanced Innovation Think-tank Program, China Association for Science and Technology, grant number: DXB-ZKQN-2017-045.

Conflicts of Interest: The authors declare no conflict of interest. The funders had no role in the design of the study; in the collection, analyses, or interpretation of data; in the writing of the manuscript, or in the decision to publish the results.

\section{References}

1. Lin, B.; Benjamin, N.I. Green development determinants in China: A non-radial quantile outlook. J. Clean. Prod. 2017, 162, 764-775. [CrossRef]

2. Li, K.; Song, M. Green Development Performance in China: A Metafrontier Non-Radial Approach. Sustainability 2016, 8, 219. [CrossRef]

3. Chang, A.-Y.; Cheng, Y.-T. Analysis model of the sustainability development of manufacturing small and medium- sized enterprises in Taiwan. J. Clean. Prod. 2019, 207, 458-473. [CrossRef]

4. Jose, A.; Lee, S.-M. Environmental Reporting of Global Corporations: A Content Analysis based on Website Disclosures. J. Bus. Ethics 2006, 72, 307-321. [CrossRef]

5. Matinaro, V.; Liu, Y.; Lee, T.-R.; Poesche, J. Extracting key factors for sustainable development of enterprises: Case study of SMEs in Taiwan. J. Clean. Prod. 2019, 209, 1152-1169. [CrossRef]

6. Orlitzky, M.; Schmidt, F.; Rynes, S. Corporate social and financial performance: A meta analysis. Organ. Study 2003, 24, 403-441. [CrossRef]

7. Zhang, $\mathrm{X}$.; Wu, Z.; Feng, Y.; Xu, P. “Turning green into gold”: A framework for energy performance contracting (EPC) in China's real estate industry. J. Clean. Prod. 2015, 109, 166-173. [CrossRef]

8. Ke, L.; Boqiang, L. Impact of energy conservation policies on the green productivity in China's manufacturing sector: Evidence from a three-stage DEA model. Appl. Energy 2016, 168, 351-363.

9. Hou, D.; Li, G.; Chen, D.; Zhu, B.; Hu, S. Evaluation and analysis on the green development of China's industrial parks using the long-tail effect model. J. Environ. Manag. 2019, 248, 109288. [CrossRef]

10. Wang, M.-X.; Zhao, H.-H.; Cui, J.-X.; Fan, D.; Lv, B.; Wang, G.; Li, Z.-H.; Zhou, G.-J. Evaluating green development level of nine cities within the Pearl River Delta, China. J. Clean. Prod. 2018, 174, 315-323. [CrossRef]

11. Yang, Q.; Wan, X.; Ma, H. Assessing Green Development Efficiency of Municipalities and Provinces in China Integrating Models of Super-Efficiency DEA and Malmquist Index. Sustainability 2015, 7, 4492-4510. [CrossRef]

12. Li, X.; Du, J.; Long, H. Green Development Behavior and Performance of Industrial Enterprises Based on Grounded Theory Study: Evidence from China. Sustainability 2019, 11, 4133. [CrossRef]

13. Jiang, Y.S. The impact of external environmental pressure and opportunity perception on corporate green performance. Sci. Technol. Prog. Policy 2015, 32, 72-76. (In Chinese)

14. Varela-Candamio, L.; Novo-Corti, I.; García-Álvarez, M.T. The importance of environmental education in the determinants of green behavior: A meta-analysis approach. J. Clean. Prod. 2018, 170, 1565-1578. [CrossRef]

15. Majumdar, A.; Sinha, S.K. Analyzing the barriers of green textile supply chain management in Southeast Asia using interpretive structural modeling. Sustain. Prod. Consum. 2019, 17, 176-187. [CrossRef] 
16. Kolk, J.E.M. Sustainability reporting. VBA J. 2005, 21, 34-42.

17. Paun, D. Corporate sustainability reporting: An innovative tool for the greater good of all. Bus. Horiz. 2018, 61, 925-935. [CrossRef]

18. Global Reporting Initiative (GRI). GRI and Sustainability Reporting. 2018. Available online: https: //www.globalreporting.org/information/sustainability-reporting/Pages/gri-standards.aspx (accessed on 30 November 2019).

19. Shields, J.; Shelleman, J.M. Integrating sustainability into SEM stategy. J. Small Bus. Strategy 2015, 25, 59-76.

20. Roca, L.C.; Searcy, C. An analysis of indicators disclosed in corporate sustainability reports. J. Clean. Prod. 2012, 20, 103-118. [CrossRef]

21. Long, Y.; Pan, J.; Farooq, S.; Boer, H. A sustainability assessment system for Chinese iron and steel firms. J. Clean. Prod. 2016, 125, 133-144. [CrossRef]

22. Siew, R.Y. A review of corporate sustainability reporting tools (SRTs). J. Environ. Manag. 2015, 164, $180-195$. [CrossRef] [PubMed]

23. Lin, R.-J. Using fuzzy DEMATEL to evaluate the green supply chain management practices. J. Clean. Prod. 2013, 40, 32-39. [CrossRef]

24. Yang, C.-S.; Lu, C.-S.; Haider, J.J.; Marlow, P.B. The effect of green supply chain management on green performance and firm competitiveness in the context of container shipping in Taiwan. Transp. Res. Part E Logist. Transp. Rev. 2013, 55, 55-73. [CrossRef]

25. Zhou, F. Study on the Implementation of Green Supply Chain Management in Textile Enterprises. J. Sustain. Dev. 2009, 2, 75-79. [CrossRef]

26. Pirraglia, A.; Saloni, D.E. Measuring environmental improvements image in companies implementing green manufacturing, by means of a fuzzy logic model for decision-making purposes. Int. J. Adv. Manuf. Technol. 2011, 61, 703-711. [CrossRef]

27. Liang, W.-Z.; Zhao, G.-Y.; Hong, C.-S. Performance assessment of circular economy for phosphorus chemical firms based on VIKOR-QUALIFLEX method. J. Clean. Prod. 2018, 196, 1365-1378. [CrossRef]

28. Li, R.H.; Su, C.H. Evaluation of the circular economy development level of Chinese chemical enterprises. Procedia Environ. Sci. 2012, 13, 1595-1601. [CrossRef]

29. Fonseca, L.; Domingues, J.; Pereira, M.; Martins, F.; Zimon, D. Assessment of Circular Economy within Portuguese Organizations. Sustainability 2018, 10, 2521. [CrossRef]

30. Domingues, A.R.; Lozano, R.; Ceulemans, K.; Ramos, T.B. Sustainability reporting in public sector organisations: Exploring the relation between the reporting process and organisational change management for sustainability. J. Environ. Manag. 2017, 192, 292-301. [CrossRef]

31. Duić, N.; Urbaniec, K.; Huisingh, D. Components and structures of the pillars of sustainability. J. Clean. Prod. 2015, 88, 1-12. [CrossRef]

32. Hellweg, S.; i Canals, L.M. Emerging approaches, challenges and opportunities in life cycle assessment. Science 2014, 344, 1109-1113. [CrossRef] [PubMed]

33. Henrikssona, P.J.G.; Beltonc, B.; Murshed-e-Jahan, K.; Rico, A. Measuring the potential for sustanable intensification of aquaculture in Bangladesh using life cycle assessment. Proc. Natl. Acad. Sci. USA 2018, 115, 2958-2963. [CrossRef] [PubMed]

34. Fonseca, L.; Domingues, J. Exploratory Research of ISO 14001:2015 Transition among Portuguese Organizations. Sustainability 2018, 10, 781. [CrossRef]

35. Cooper, J.S. Life cycle assessment and sustainable development indicators. J. Ind. Ecol. 2009, 7, 12-15. [CrossRef]

36. Sánchez, A. Perspectives and problems in sustainable development. Probl. Sustain. Dev. 2008, 3, 21-23.

37. Dowie, T. Green Design. World Class Des. Manuf. 1994, 1, 32-38. [CrossRef]

38. Tabone, M.D.; Cregg, J.J.; Beckman, E.J. Sustainability metrics life cycle assessment and green design in polymers. Environ. Sci. Technol. 2010, 44, 8264-8269. [CrossRef]

39. Rossi, M.; Germani, M.; Zamagni, A. Review of ecodesign methods and tools. Barriers and strategies for an effective implementation in industrial companies. J. Clean. Prod. 2016, 129, 361-373. [CrossRef]

40. Altal, M.; Florida, R. Green manufacturing. In Handbook of Technology Management; McGraw-Hill Professional: New York, NY, USA, 1998; pp. 1385-1393.

41. Seth, D.; Rehman, M.A.A.; Shrivastava, R.L. Green manufacturing drivers and their relationships for small and medium (SME) and large industries. J. Clean. Prod. 2018, 198, 1381-1405. [CrossRef] 
42. Xia, D.; Zhang, M.; Yu, Q.; Tu, Y. Developing a framework to identify barriers of Green technology adoption for enterprises. Resour. Conserv. Recycl. 2019, 143, 99-110. [CrossRef]

43. Maruthi, G.D.; Rashmi, R. Green Manufacturing: It's Tools and Techniques that can be implemented in Manufacturing Sectors. Mater. Today Proc. 2015, 2, 3350-3355. [CrossRef]

44. Chhabra, D.; Garg, S.K.; Singh, R.K. Analyzing alternatives for green logistics in an Indian automotive organization a case study. J. Clean. Prod. 2017, 167, 962-969. [CrossRef]

45. Seroka-Stolka, O. The Development of Green Logistics for Implementation Sustainable Development Strategy in Companies. Procedia Soc. Behav. Sci. 2014, 151, 302-309. [CrossRef]

46. Ubeda, S.; Arcelus, F.J.; Faulin, J. Green logistics at Eroski: A case study. Int. J. Prod. Econ. 2011, 131, 44-51. [CrossRef]

47. Magnier, L.; Crié, D. Communicating packaging eco-friendliness: An exploration of consumers' perceptions of eco-designed packaging. Int. J. Retail Distrib. Manag. 2015, 43, 350-366. [CrossRef]

48. Glavič, P.; Lukman, R. Review of sustainability terms and their definitions. J. Clean. Prod. 2007, 15, 1875-1885. [CrossRef]

49. Wang, B.; Ren, C.; Dong, X.; Zhang, B.; Wang, Z. Determinants shaping willingness towards on-line recycling behaviour: An empirical study of household e-waste recycling in China. Resour. Conserv. Recycl. 2019, 143, 218-225. [CrossRef]

50. Tseng, M.-L.; Islam, M.S.; Karia, N.; Fauzi, F.A.; Afrin, S. A literature review on green supply chain management: Trends and future challenges. Resour. Conserv. Recycl. 2019, 141, 145-162. [CrossRef]

51. Liu, L.; Zhang, M.; Ye, W. The adoption of sustainable practices: A supplier's perspective. J. Environ. Manag. 2018, 232, 692-701. [CrossRef]

52. Gabathuler, H. The CML Story: How Environmental Sciences Entered the Debate on LCA. Int. J. Life Cycle Assess. 2006, 11, 127-132. [CrossRef]

53. Thinkstep. Software Gabi. Available online: https://www.thinkstep.com/ (accessed on 30 November 2019).

54. Wang, X. The Overall Utilization Rate is Only 15\%. 2018. Available online: https://www.tnc.com.cn/info/c001001-d-3655856.html (accessed on 30 November 2019).

55. Rafiaani, P.; Kuppens, T.; Thomassen, G.; Van Dael, M.; Azadi, H.; Lebailly, P.; Van Passel, S. A critical view on social performance assessment at company level: Social life cycle analysis of an algae case. Int. J. Life Cycle Assess. 2019. [CrossRef]

56. Dreyer, L.; Hauschild, M.; Schierbeck, J. A Framework for Social Life Cycle Impact Assessment. Int. J. Life Cycle Assess. 2005, 11, 88-97. [CrossRef]

57. Dreyer, L.C.; Hauschild, M.Z.; Schierbeck, J. Characterisation of social impacts in LCA part 2 implementation in six company case studies. Int. J. Life Cycle Assess. 2010, 15, 385-402. [CrossRef]

58. Fu, J.; Geng, Y. Public participation, regulatory compliance and green development in China based on provincial panel data. J. Clean. Prod. 2019, 230, 1344-1353. [CrossRef]

59. Yuan, H.; Zhang, T.; Feng, Y.; Liu, Y.; Ye, X. Does financial agglomeration promote the green development in China? A spatial spillover perspective. J. Clean. Prod. 2019, 237, 117808. [CrossRef]

(C) 2019 by the authors. Licensee MDPI, Basel, Switzerland. This article is an open access article distributed under the terms and conditions of the Creative Commons Attribution (CC BY) license (http://creativecommons.org/licenses/by/4.0/). 